\title{
Transgender Microcelebrity Activists: Self-Broadcasting as Politics
}

\author{
Kyle Humphreys ${ }^{1}$ and Jin Kim \\ ${ }^{1}$ The college of Saint Rose, Albany, NY, USA \\ \#Advisor
}

ABSTRACT

This research is a qualitative study of Natalie Wynn and Blaire White, two transgender women who empower themselves and their viewers via social media. I hypothesize garnering online audiences and social media popularity through demonstrations of authenticity, connectedness, and accessibility can be translated into a social currency for activism. Transgender microcelebrities use their influence to disseminate ideas pertaining to their political ideologies. I examined the transgender microcelebrities' Instagram accounts and YouTube videos via Raun's (2018) framework for microcelebrity practices based on observations of self-celebrification on YouTube. The observed content was then examined through a political activist lens using framework from Daskal (2017) on digital rights activism to demonstrate how their microcelebrity practices are a form of digital activism.

\section{Introduction}

It is difficult to discern how many transgender individuals exist. A 2016 study from the Williams Institute utilizes data from the CDC's Behavioral Risk Factor Surveillance System (BRFSS) to estimate the number of transgender identifying individuals in the United States to be 1.4 million adults. This survey does not account for individuals who have undergone medical and social interventions to live as their assigned gender and may not identify as transgender and individuals who were not comfortable disclosing their gender identity. As time passes and societal acceptance of discarding one's assigned gender improves, the prevalence of transgender individuals could increase or appear to as more individuals feel safe identifying or disclosing their gender identity. The BRFSS survey was an elective survey conducted via cellular and landline phones, so it must be emphasized that there could be more than 1.4 million transgender adults (Flores et. al 2016).

Despite federal protections against discrimination on the basis of gender identity, transgender people face discrimination in every facet of life. A survey of over 6,000 transgender individuals in the United States \& its territories conducted by The National Gay and Lesbian Task Force and the National Center for Transgender Equality found that discrimination was pervasive in education, employment, housing, justice involvement, family, and health care. Anti-transgender biases make transgender people a vulnerable population to poverty, homelessness, mental illness, isolation, and violence. Transgender people are four times more likely than the general population to have an annual income under $\$ 10,000$ and twice as likely to experience unemployment (Grant et. al 2011). Legislation that targets transgender individuals exacerbates these issues and puts transgender individuals at greater risk of harm (Cox 2021), increasing the need for transgender education to challenge gender biases.

The internet is an effective form of broadcasting one's voice and presence. With the advent of participatory media technologies and content platforms like YouTube, transgender individuals can empower themselves and be responsible for their representation. Raun (2010) theorizes this behavior results from transgender individuals having to submit themselves to evaluations and labels to access medical care or resources to live as they need. Performing in front of a camera also allows transgender people to practice their gender presentation and experiment with their expression. Participatory platforms that host self-authored transgender content become resources for those seeking to 
expand their knowledge about transgender identity, transitioning, and what being transgender means in a transgender hostile society. Developing this amateur knowledge base is crucial considering that the earliest transgender research was demolished decades ago. Magnus Hirschfeld, a pioneering gender and sexuality researcher of the early 1900s, lost his institute and its library of research when Nazi vigilantes demolished it in 1933. Today, transgender people are in control of their narrative with videos and blogs (Stryker 2017). While there are many rising transgender celebrities and activists, including Laverne Cox, Chelsea Manning, Jazz Jennings, and Gavin Grimm, there is no uniform transgender experience. Sharing oneself or story online diversifies the existing body of transgender knowledge.

Social movements are defined as networks of individuals or groups/organizations sharing a collective identity engaged in a political or cultural conflict with common grievances (Diani 1992). Individuals in social movements act towards a concerted goal or interest. While some social movements are defined, such as \#freethenipple or \#metoo, transgender activism has numerous grievances with the standard of living for transgender individuals. There is no one set hashtag or label for this movement, but the collective identity of being transgender in an overwhelmingly cisnormative society that reacts violently towards gender deviancy is present. Utilizing the internet as a platform for advocacy has two facets: the allowance or facilitation of offline activities, and internet-based virtual actions (Van Laer \& Van Aelst 2010).

Cammaerts (2018), in a study of social media and activism, stated "the emergence of digital networked technologies has led to the convergence of channels of distribution and communication formats including social media." Despite social media not being designed to coordinate movements and protests, it is often employed to do so. Media of multiple mediums can be distributed with ease between platforms. Social media has become a massive distribution platform for multi-media content, allowing consumers to reach hundreds of thousands of people regardless of distance. Social media and similar participatory platforms like YouTube rely on this self-broadcasting to populate their sites with content. Given the internet's prevalence in day-to-day life, disadvantaged groups can find community and influence on participatory platforms. Online communities and knowledge-sharing platforms can directly benefit racial, cultural, economic, and gender minorities (Matich et. al 2019). A transgender person who is physically isolated from other transgender identifying individuals can find community online and, by extension, a safe place to discuss and explore their identity with more openness than they may be able to practice offline. With this understanding, the collective documentation and self-expression of transgender individuals online through participatory platforms is social activism. There is a loosely coordinated effort to self-advocate and inform an unknowledgeable public about transgender identities, where individuals can engage at their discretion regardless of formal affiliations. This converging over the internet around held beliefs and a perceived conflict is a social movement (Diani 1992). Digital activism is a popular form of activism given its accessibility. Hundreds to thousands of individuals can be mobilized within minutes or clicks regardless of locale.

Media activism has three major functions for a social movement's success: mobilization, validation, and scope enlargement. Movements thrive through media as they gain traction and an audience, as media allow for broadcasting to occur. Broadcasting allows for a response in the form of mobilization, critique, or continued broadcasting of said issue at either a micro or macro scale. Dissemination of political information can enlarge the scope of a movement and validate the cause in the eyes of followers and supporters outside the movement (Gamson \& Wolfsfeld 1993). Daskal (2018) studied the activity of civil-society organizations centered around digital rights, including access to the internet, freedom of speech, and the right to privacy. In analyzing the content of four organizations, Daskal concluded they operated on three principles: cultural informational framing, personal activism, and branding digital rights activism. Cultural informational framing is a persuasion tactic used in media messages disseminated by an actor or group to benefit a social movement. Personal activism encourages individuals to act on behalf of a social movement to engage the greater public. To brand activism can make one's movement appear trendy and garner additional financial support for a cause. Supporters can feel a sense of community, and purchasing merchandise makes donating a transactional experience. Wearing a brand is a form of self-expression, and expressing support for a movement increases the audience for brand messaging. 
The transformative capacity of the internet is present not only in how individuals find community, but how these technologies enable consumers to become creators. The ability to self-broadcast has inspired a new form of selfentrepreneurship in which any individual can attain audience or celebrification. In a case study of a beauty and lifestyle vlogger turned microcelebrity, Jerslev (2016) determined authenticity as the attractive factor for followers of microcelebrities. Microcelebrities differ from typical celebrities in their connections with their audience and branding of self. "Celebrification," or the commodification of the self through social and cultural performance allows individuals to gain fame online. In a study of a transgender vlogger documenting her medical transition for YouTube, Raun (2018) found microcelebrities engage in self-celebrification when expressing accessibility, availability, presence, connectedness, and most importantly authenticity with their viewing audience. Authenticity can come in the form of self-disclosure or surrendering of privacy to discuss personal details with an audience as though they were a confidant. Emotional labor is the largest component of self-celebrification, as the personal investment in the brand and audience is what endears the audience to the creator. This devotion to the craft and fanbase is a common theme of microcelebrities, especially in feminist bloggers. Women who amass large followings online are frequently heralded as entrepreneurs, being the boss of their media business. This is a major part of branding and can be found in microcelebrity behavioral patterns (Duffy \& Hund 2015).

\section{Methods}

To provide a deeper understanding of transgender activism on social media, I chose Natalie Wynn and Blaire White as subjects for analysis. Wynn and White are transgender women who utilize participatory media to broadcast messages advocating for transgender people based on their personal beliefs. Wynn (2011) manages the YouTube channel Contrapoints where she publishes video essays on numerous topics, utilizing set design and acting to communicate ideas from various perspectives. While the idea of one person playing numerous characters is not new, Wynn's use of characters to explore ideology and arguments adds novelty to the concept. White's (2015) approach to vlogging on YouTube is more informal and personal in execution. She establishes a connection with her viewers in simple settings like her bedroom or closet. Speaking authoritatively on news and developments involving the transgender community, she has established herself as a conservative transgender woman seeking to set an example for transgender people. Despite their shared gender identity, they hold different beliefs about what transgender is and what is best for the transgender movement. Given their apparent differences, it produces diverse results reflective of how varied the transgender experience is. Daskal (2018) found activists educate and engage citizens in social movements, which Wynn and White do in their respective way. Understandings of microcelebrity practices as requiring accessibility, authenticity, and connectedness (Raun 2018) will be referenced to establish Wynn and White as microcelebrities with an audience for their activism. Beyond qualitative analysis of digital activism and microcelebrity practices, I have also gathered quantitative data from their Instagram posts and YouTube videos for demonstrations of microcelebrity practices and implicit or explicit engagement of followers in social activism.

I analyze Wynn's and White's social media content posted between May 2019 and June 2021 from their Instagram and YouTube respectively for aspects of both activism, branding, and microcelebrity practices. Select posts from Instagram are analyzed in detail as to demonstrate the brand specific messaging and voice each individual possesses. To quantitate microcelebrity practices, I have created four categories with which to assign posts as they relate to microcelebrity behavior: connectedness, promotion, self-disclosure, and the ordinary. Posts can fall under more than one category, and will be rounded to a percentage to account for different amounts of posts within the May to June timeframe. Connectedness will be counted if the viewer is invoked, either through description or by making eye contact with the audience. Promotion will be counted in posts that discuss upcoming content or announcements relevant to the brand such as collaborations or media features. Personal matters will be considered self-disclosure when the post involves the surrendering of privacy to discuss serious topics with the reader. Posts that are ordinary will exemplify moments in which the author appears accessible to an ordinary viewer. Merchandising for both individuals 
will also be analyzed for aspects of activism \& branding as defined by Daskal (2018), recognizing the self becomes an activist or otherwise political figure in small social groups (i.e. transgender individuals).

The videos chosen from Natalie Wynn's channel, Contrapoints, include "Pronouns", "Tiffany Tumbles", "Voting", "Beauty", and "Transtrenders". Videos from Blaire White's channel for analysis include "THIS is Why the Trans Community Isn't Respected (RANT)", "The Truth About Why I'm Still Not A Parent", "My Life Felt Ruined" - Talk w/ Detransitioned Woman", "Responding to 'Blaire White Hates Non-Binary People"”, and "TRUMP REMOVING TRANS RIGHTS?? (The Truth)". The video choices were chosen at random as long as they fell within the timeframe as defined above, a period of time with significant events took place that affected the transgender community in ways the microcelebrities reflect on to their audience. The videos must pertain to transgender dialectics or discuss transgender issues as they relate to events within that timeframe and be over 15 minutes in length to ensure there would be enough content for analysis. YouTube content will be analyzed for demonstrations of presence, connectedness, and authenticity.

\section{Results}

\section{Information and Symbolic Politics}

Cultural informational framing is a persuasion tactic of activist organizations to persuade and engage potential supporters. This method can be divided into two factions: information politics and symbolic politics. Information politics is an activist's ability to generate politically relevant content and promote it at a time and place where it will have a great impact at a critical time. Symbolic politics operates by evoking symbols, actions, and stories to drive an audience to invest and resonate with the content. Cultural information framing is exemplified by a combination of both information politics and symbolic politics (Daskal 2018).

Wynn balances her informational politics with recent events and personal experiences. Her videos are comprised of factual analysis and comparison, rather than being weighted by personal anecdotes alone. "Pronouns" is a strong example of her ability to deliver informative politics. The subject of her video was the nature and usage of pronouns as sensationalized by a relevant and recent figure, Ben Shapiro. Shapiro is a young conservative figure known for challenging "leftist ideology" (Tavernise 2017). Wynn deconstructs Shapiro's arguments to discuss pronouns to viewers with varying levels of understanding, while also enabling viewers to relate with light symbolic politics by discussing her experiences and those of Blaire White. She draws upon linguistics, social etiquette, and biological arguments made against referring to transgender people by the pronouns they request to be called (Wynn 2018a). Drawing upon a relevant figure in mainstream media to discuss a continual issue in transgender civil rights is symbolic and informational accordingly.

A tactic Wynn utilizes to persuade her audience in a major way is to speak to their knowledge or lack thereof. Through parody and an interpersonal debate staged between characters she plays, Wynn (2019c) embodies the overarching fear the general public holds towards gender nonconforming individuals. In "Transtrenders", Wynn plays the recurring character Jackie Jackson, host of a fictional show titled The Freedom Report, where she brings on guests to debate various topics. Jackie's inability to pick a "side" in political debates serves to facilitate discussions between more politically charged characters. Her lack of substantial knowledge makes her susceptible not only to negative ideation towards transgender people but also to positive ideation. The other characters Jackie invites for debate include Tiffany Tumbles and a non-binary person named Baltimore Maryland. Tiffany believes being transgender is a diagnosable medical illness, where Baltimore understands binary gender as being too restrictive to the ways people can and do express themselves. By providing characters from three different perspectives on transgender issues, Wynn can speak to audience members from numerous sides of the spectrum and encourage self-reflection. Though she does not draw upon any specific moment or event, transgender issues are often a point of contention. 
Disagreements are common in communities as large as the transgender community, and Wynn addressed this continual divide through staged debate. These characters explicitly embody symbolic politics; each persona is symbolic of a different ideology regarding transgender individuals. This explicit symbolism through characters is a consistent theme in her videos. Tiffany Tumbles initially debuts in a video named after herself, where she visits the set of The Freedom Report for a debate. Wynn establishes Tiffany's character as someone obsessed with the concept of passing, tearfully abusing substances after reading transphobic comments about her appearance on The Freedom Report. She believes conforming to traditional ideas of feminine expression set by cultural standards to gain public approval is her burden to bear, an ideology comparable to that of Blaire White (Wynn 2018a). This blatant parody is mocks the micropolitics that proliferate the transgender community online.

Most of White's videos are sensational in nature and draw upon recent stories, symbols, and individuals to garner support for her perspectives. Many followers of White anticipate her opinions on recent news and topics of contention within the transgender community. Prefacing her video on whether the Trump administration would be repealing trans rights, White (2018) claims numerous people were asking her to make a video following the release of a New York Times article about how the administration sought to establish definitions of sex. The article (Green, et.al. 2018) describes a memo from the Department of Health and Human Services seeking to define gender as purely biological under Title IX in an attempt to enforce restrictive understandings of gender as male or female to be refuted only by genetic testing. This would affect the civil rights of millions of Americans who identify as transgender. White (2018) summarizes the memo with her understanding of the issue to put her viewers at ease. She also claimed the government had no authority over the dictionary definition for transgender individuals, and such legislation would not change anything. This video exemplifies the symbolic politics in her addressing transgender people by name for expressing fear of being erased by this potential administrative action and using the New York Times article as a talking point. It is informational as the video was released during the 2018 midterm voting season, making it a culturally relevant time to discuss.

Positioning herself as a figure of authority on transgender issues, the recipients of her message will be convinced in favor of her perspective, especially if her voiced opinion speaks to their concerns or values. In an off-thecuff video, White (2021d) comments on anti-transgender rhetoric and theorizes transgender people are not receiving the same acceptance gay people have in recent years because they are pushing against societal standards too hard. She uses very charged language, saying transgender people are "science deniers" and spread "blatant lies", discussing how biology relates to the understanding of transgender people. She proposes what she believes is a more nuanced direction the transgender community needs to achieve acceptance from society. White's argument fails to define what acceptance looks like for transgender people and what desired progress can be achieved by catering to the perceptions of cisgender heterosexual individuals. Though she acknowledges housing and employment discrimination are a reality for transgender people, she is concerned with the pragmatics of transgender goals. In this informal tangent, White utilizes symbolic politics by drawing upon patterns of behavior and repeated sentiments about transgender people to advocate for her position. The publication of this video promotes informational politics, as 2021 is a record year for proposed legislation that would significantly harm transgender young adults in the United States. The future for transgender individuals remains uncertain as the Senate had yet to vote on amending the 1964 Civil Rights Act at the time this video was published. Proposed amendments to the bill would explicitly include gender identity and sexual orientation as protected identities (Krishnakumar 2021).

White may invite guests to share their experiences, expertise, and opinions for her videos. One guest, Grace Lidinsky-Smith, transitioned from female to male and back to female. People who medically transition with regret are termed "detransitioners" and are a small percentage of people who transition. These stories are weaponized to fabricate a narrative positing transgender people as disillusioned (Urquhart 2021). White (2021a) was interested in LidinskySmith's story after she was featured on the television show 60 Minutes and invited her for an interview about LidinskySmith's documented detransition under the alias HormoneHangover. White brought attention to a taboo in the transgender community through this video with the relevant media attention Lidinsky-Smith was receiving. Detransitioning is a critical topic in 2021 as numerous states consider and pass legislation to decrease the accessibility of 
transgender healthcare for people under the age of 18 (Cox 2021). This cultural relevance and use of Lidinsky-Smith as an example or symbol for detransitioning demonstrate White's ability to engage in cultural informational framing of her activism.

According to Daskal (2018), personal activism is the involvement of an audience in a social movement through activism such as petition signing, urging them to contact representatives, and participating in the dissemination of material pertaining to their campaign. When discussing the leaked memo from the Department of Health and Human Services, White (2018) encouraged her American viewers to vote in the upcoming midterms and to read beyond headlines to be an informed participant in democracy. Though all of her videos do not encourage personal activism, Wynn advised her viewers to vote during the 2020 election to oust Trump in her video titled "Voting." She spends the video discussing the symbolic nature of what she describes as radical leftist ideology and suggests voting as one tenant of becoming an active citizen to encourage systemic change by showing viewers how to register to vote and find their polling site. The video was released in October, just under a month before the presidential election (Wynn 2020b).

When the Department of Health and Human Services memo regarding gender and sexuality definitions leaked, \#wearehere began trending, affirming transgender people will not disappear if definitions do. Experts affirmed proposed changes to Title IX would make it harder for transgender people to access care, and easier for service providers to deny transgender people on the basis of gender identity. Wynn (2020a) took to her Instagram and shared a video with the caption, "The Trump Administration wants to make it legal to fire workers just because they are LGBTQ+. As you read this, the Supreme Court is considering our rights. IF you want to fight for LGBTQ+ rights and justice, spread the word \#WeAreHere. Watch this video to learn more." The video informed people about the proposal made by the administration and included appearances from numerous transgender figures, including Wynn herself. This Instagram post is an example of personal advocacy, as Wynn encouraged the promotion of the hashtag to raise awareness and send a message to the administration.

\section{Branding}

Branding is an essential part of activism. One's presence and purpose must be compelling to ally an audience with those who advocate their political agenda. Activism branding may include merchandising, "phraseology" or slogans (Daskal 2018). Personal branding is curtailing one's image to evoke a particular emotional response from their audience (Deckers \& Lacy 2018). Branding oneself and affiliated social movement(s) work in tandem for microcelebrity activists. Viewers and supporters can financially contribute to people based on shared views and express support through merchandising.

Wynn captures her viewers' attention by investing in lavish outfits and costumes, colored lighting, and settings meant to bring her characters to life. These characters are featured in her online store on posters and wearables with quotes from her videos. Easy to spread and share for their messages and ideas, these characters have become a part of Wynn's brand. Several designs outright name her channel, explicitly establishing her brand and style. Some of the illustrations incorporate aspects of her set design and use of dual-color lighting (fig 1a). The use of her personal branding in merchandising is commercialization of the self, though given the political nature of her content and designs this can be considered activist branding. Wynn is disseminating material relating to ideas she expresses through her characters and set design. Though some context is required for a picture of a cat wearing a wig with the text, "This cat kills fascists," it could open up dialogues with observers to disseminate ideas without any direct involvement from Wynn (TeePublic n.d.).

Blaire White's merchandising also makes use of slogans and phraseology. Her positions on transgender issues have attracted criticisms from those who are in opposition, and in response she champions being "Uncancelable," maintaining her platforms and continuing to self-broadcast to a growing audience. Selling this idea on a shirt speaks to her personality and brand. Designs featuring images of her include other phraseology from her videos, establishing her influence and popularity (fig 1b). Some of her merchandise for sale features her name and none of her imagery, 
establishing Blaire White is a brand followers will adorn to express support for her and her views. Other slogans on her shirts expressing her ideology disseminated in her videos include "STRAIGHT WHITE MALE" and "Hello, my pronouns are THAT/BITCH." A commonality between many of the designs is a shade of pink, a color often associated with femininity (Spring n.d.). This glamorization and traditional presentation of femininity are core to her brand and beliefs on how to present femininity. The casual and low-production value of her videos is reflected in her designs as well.

Figure 1.
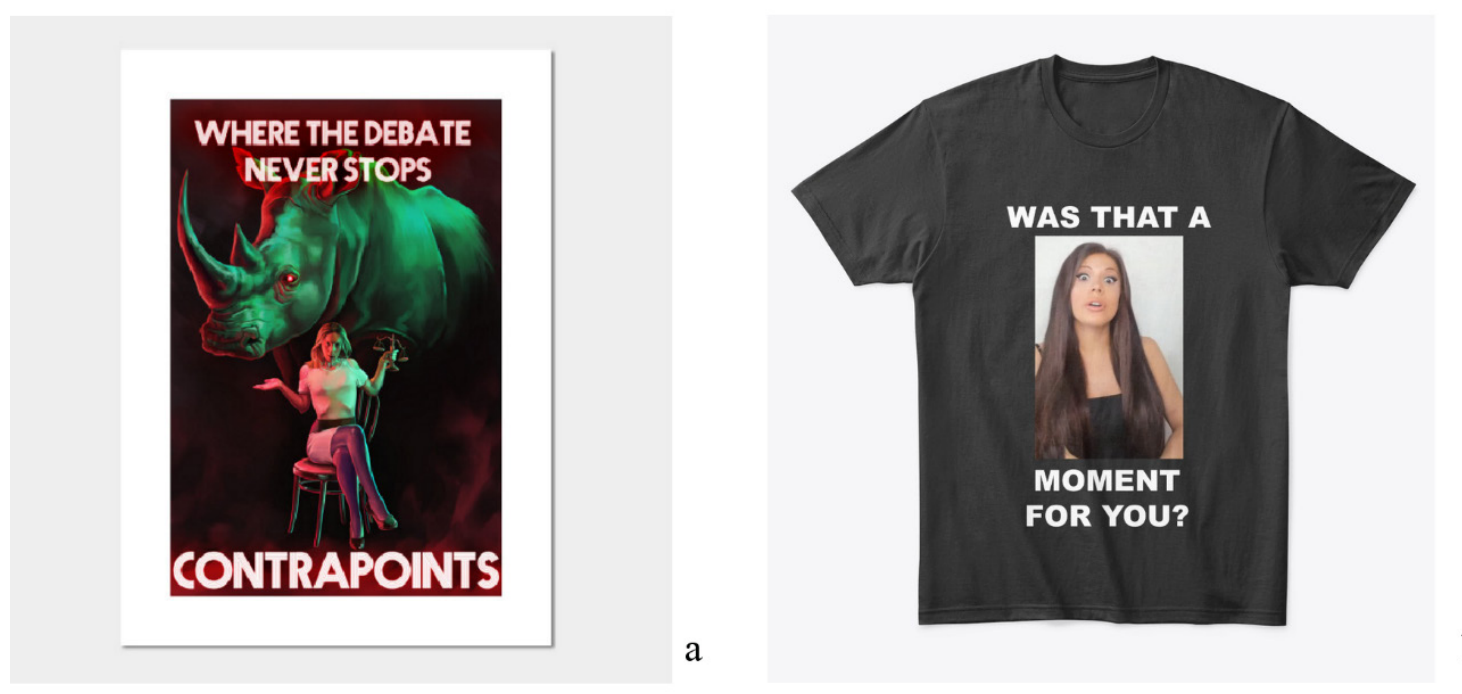

b

Note. Figure 1a is a poster mockup available for purchase on Wynn's TeePublic (n.d.) storefront. Figure $1 \mathrm{~b}$ is a t-shirt mockup available for purchase on White's Spring (n.d.) storefront.

\section{Instagram}

When they are not uploading new YouTube videos, Wynn and White maintain their presence on social media. They both utilize Facebook, Twitter, and Instagram to connect with their audience and notify their followers of upcoming or new content. In their Instagram profile descriptions, they leave a link to their most recent content, whether it is a media feature or their latest video. White makes use of the Instagram Stories Highlights feature to advertise her merchandise, latest video, Twitter, and podcast. She also has a story titled "My life" with loops, photos, and videos from her previous stories. Most of her Instagram pictures are photos of herself posing in swimwear or with friends, comprising more than half of the 64 posts she made between May 2019 and June 2021 (White n.d.). Manicuring the content of her Instagram page to showcase her lifestyle establishes online presence and makes her appear accessible. The ordinariness of her "My life" reel of time spent with friends and family signals to the viewer that despite the fancy cars and glamour, she is not above ordinary things.

Although her photos appear staged and inauthentic, she makes herself appear flawed through selective selfdisclosure of her personal life in the text portion of posts. In one post with two photos of her in a luxury vehicle, White (2021a) discusses her eating disorder; "I took these pics a couple months ago on vacation and refused to post them because my brain convinced me I looked HUGE in them. I came across them again with a clearer mind and obviously that's not the case. Anyway, stop being so hard on yourself!" The honesty in which she shares her experience having an eating disorder establishes authenticity as well as connectedness with any audience members with eating disorders; they now perceive a commonality between White and themselves. Another post where White's disclosure establishes a commonality with her fans was from July of 2020 during the Coronavirus pandemic that shut down much of the 
country and the larger world. No longer able to see friends in person, many people looked to the internet to socialize and connect. White (2020b) shared a poolside photo of herself in a swimsuit with a cold beverage, captioned "Trying to enjoy the summer from hell where everything online + real life feels so dark and scary $\odot$." This caption demonstrates how despite her influence, White was experiencing grief and stress related to the global lockdowns like any of her other followers.

Between May 2019 and June 2021, Wynn posted over 60 times to Instagram. When she isn't posting selfies of new outfits or photos taken for magazines, Wynn teases new upcoming videos with set photos and character previews. Nearly 30 of her posts show Wynn making eye contact with the camera lens, and by extension the viewer. Establishing eye contact acknowledges the viewing audience, creating an active connection to her fans. These eyecontact photos are not only everyday selfies of her as herself, but also when she is costumed as a character from her YouTube channel (Wynn n.d.).

Wynn creates the appearance of self-confidence through her posture on camera, yet discloses moments of insecurity with her followers. On the third anniversary of her transition, Wynn (2020c) disclosed to her fans that the third year was the hardest. She does not disclose her reasons for feeling this way, but for many trans people who struggle with insecurity it can be a comfort to know even your idols struggle similarly. Her display of vulnerability creates the appearance of authenticity and allows followers who struggle in their transitions to feel connected in the struggle for self-approval. Though she has the approval and adoration of many followers, self-acceptance is a continual challenge for transgender individuals. This instance of self-criticism is not isolated; another photo Wynn shared was an unused frame from a video she had published recently titled "Opulence". Wynn expresses her concerns with her public image in the description:

Is there a certain amount of narcissistic transsexual preening? Sure. But all women must cope with visual scrutiny. If you work in a visual medium and in the public eye, it's more intense. And if you're living out your transformation onstage, it's hard not to lose yourself to your own image, to the only thing about yourself that often seems to matter. So I've had the plastic surgery, and I've created a colorful fantasy world. But the truth is, I'm never going to be the most beautiful woman, and I'm only getting older from here. I can't make it on image alone (Wynn 2020a).

This reinforces Raun's (2010) idea of "screen-birth" for transgender individuals, as well as the pressures accompanied with self-disclosure online. These pressures are magnified for transgender people, who face pressure to present their gender in a way that does not invite harm or discrimination. Conceding the idea of intimacy as having layers, her audience will only know so much of her cognitions resulting from the uniqueness of her experiences transitioning on camera. Even so, this post communicates selective intimacy with her audience to maintain the parasocial nature of the microcelebrity relationship between creator and audience, and vice versa.

Between video publications, Wynn's teasing of upcoming videos glamorizes the personal labors and selfentrepreneurship her video production requires. A photo she shared in April of 2020 shows her in ordinary wear hanging decorations in a set resembling the interior of a circus tent. She says she can't promise a release date, but promises a big show and uses circus tent emojis in the description (Wynn 2020b). Providing glimpses into the construction of set designs and development of thematic characters signals devotion to her craft, a hallmark of feminist entrepreneurship for online influencers who grow and maintain an audience (Duffy \& Hund 2015).

Figure 2. 


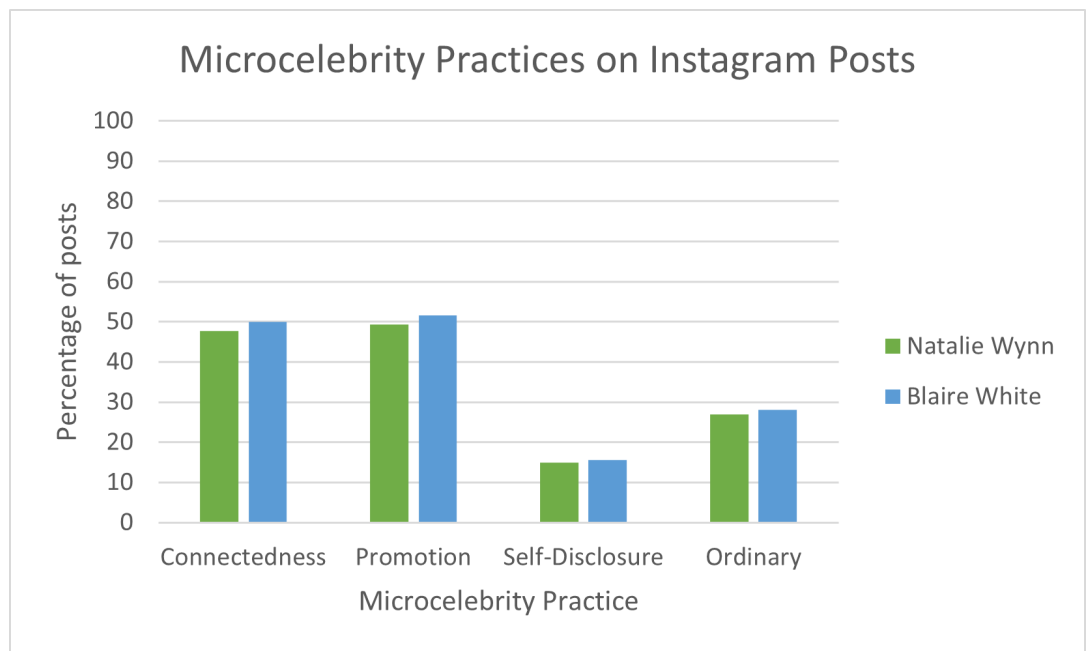

Note. Figure 2 is a chart demonstrating the percentage of analyzed posts that displayed microcelebrity practices.

To fairly assess microcelebrity demonstrations between their posts, behaviors were measured by percentage as the number of posts within the timeframe differed. An Instagram post analysis was not restricted to visual media, but the text accompanying the image as well. The post could invoke connectedness with the audience by image, but not through accompanying text. An example of this could be an image with eye contact establishing connection with the viewer, but the text could relate to an upcoming video. This post counts for both connectedness and promotion and is recorded as such. A post may be ordinary if there is no lavish or extraneous set design and manner of presentation, but be considered self-disclosure if the content of the post contains vulnerable or personal information. This graph illustrates the relative consistency between their practices in Instagram postings as they relate to Raun's (2018) observations of self-celebrification practice. While self-disclosure does not present itself in a significant number of posts when compared to demonstrations of connectedness and promotion of the personal brand, it is more prominent in YouTube videos.

\section{YouTube}

Through their YouTube channels, both White and Wynn demonstrate presence, connectedness, and authenticity through intimacy in their content. The emotional labor required to achieve these tactics are essential to their success as transgender microcelebrities. Relevant videos from their YouTube channels regarding transgender issues demonstrate the practices defined by Raun (2018).

Natalie Wynn's video essays entertain viewers through costuming and characters portrayed by herself. With financial assistance from her fans, her videos have high production value in their settings, lighting, costumes, and props. Even through frivolity, Wynn's scripts and narrative allow her to establish common ground with the audience. In much of her video essays, "Pronouns" for example, she directly acknowledges the viewers by greeting the audience as though they were within physical proximity of her (Wynn 2018a). Even when she is playing characters communicating between one another, as in "Transtrenders", her characters still establish connectedness with Wynn's audience (fig 3a). Explicitly, her characters make eye contact with the viewer, and implicitly, her characters address the various ideological perspectives of her audience. Baltimore Maryland is a new character Wynn debuts in "Transtrenders" who serves as a stand-in for non-binary viewers and the nature of non-binary identity as perceived by Wynn. Baltimore argues with Tiffany Tumbles about the nature of gender and non-binary identities in the video (Wynn 2019b). Acknowledgment of the audience establishes the connectedness required to gain and maintain an audience. The ease in which viewers can seek out connectedness makes Wynn appear accessible. 
At the beginning of each of her videos, White greets the viewers and welcomes them back to her channel. She expresses gratitude for her fanbase for allowing her to continue producing videos with their support. This appreciation for viewers makes viewers feel personally connected to White as though she finds value in them. When she speaks, she invokes the audience using "we", "I" and "you" to establish a personal connection with the viewer. Viewers can connect with White's screen presence, as she often films herself in casual settings around her home (fig $3 b$ ). The ordinary nature of her presence makes her appear more accessible; viewers can relate to the ordinary nature of her presentation. She has no extraordinary credentials to separate her from scholars or celebrities and speaks casually, allowing her identity and passion to affirm the truth of her messages. Observations and sensationalized stories carry her arguments, and her followers trust her based on the confidence with which she speaks and lived experiences as a transgender person.

A video example of her connectedness is her response to claims that she hates non-binary individuals. Nonbinary individuals are transgender people who identify outside the binary understanding of gender as being male or female. Fans of White believed she had negative feelings towards people with non-binary identities, and she makes this video to clarify things her fans said when she was playing video games with them in her private Discord server. White tells her fans she doesn't understand non-binary identities and finds pronouns outside of she and he to feel unnatural. She shares her experiences as a binary trans person and her reasonings for thinking the way she does, but she says she does not harbor any hate for non-binary people. She will try to use the pronouns non-binary people request to be called and elaborates on why she feels differently towards non-binary people (White 2021c). Responding to the thoughts of her fans shows she is connected with her fanbase and maintains this connection with seriousness. Her viewers give her the influence that she has, and she signals to them their value by addressing their concerns.
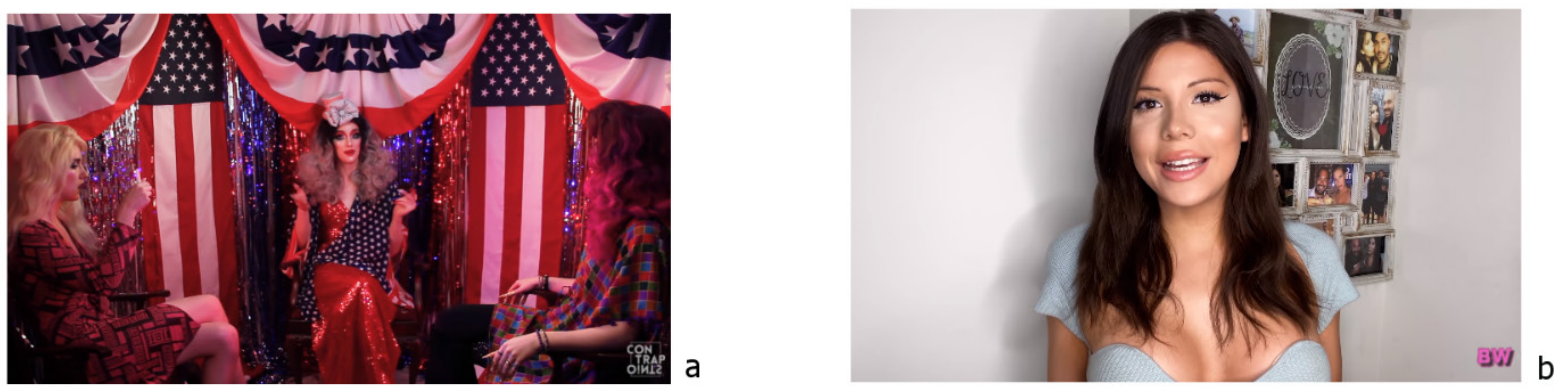

Note. Figure 3a is a still from 1:03 of "Transtrenders" (Wynn 2019b). Figure 3b is a still from 0:11 of "THIS is Why the Trans Community Isn't Respected (RANT)” (White 2021d).

On camera, Natalie Wynn refers to herself as "Ms. Points (Wynn 2018a)" if not by her name. This screen performance, or transformation into a figure, is celebrification of self. Wynn (2019a) is cognizant of this self-celebrification and intimate disclosure with her audience, at one point sardonically remarking on the intimacy of beauty vloggers by speaking to the unseen audience:

I just wanna [sic] be upfront with you guys and let you know that I've had some facial surgery. I'm always gonna [sic] be honest with you guys about this kind of thing because you mean so much to me. Like you've been here with me since the beginning, and you've seen my story, my whole entire journey, this journey I've been on as a transgender woman. You've been with me on this whole journey. This is my truth, and you've accepted the truth of my journey. 
This intentional disclosure is platitudinous to Wynn, but her character is consistently transparent with her audience and self-disclosing. In the video, Wynn describes her facial feminization procedure and reflects on the nature of beauty and gender performance. Facial feminization surgery is a broad term for various plastic surgeries trans women may receive so their face has a more feminine appearance. Bone was shaved on White's nose, forehead, chin, and trachea, also known as the "Adam's apple”. While plastic surgery is not a particularly private subject for cisgender individuals, medical transition for transgender individuals is often considered a private matter. These surgeries allow transgender people to feel and appear more "authentic", or cisgender, erasing perceived "tells" that the individual was not born as the gender they present themselves.

Revealing private information is one of the key strategies of microcelebrities (Duffy \& Hund 2015), and discussing a sensitive medical procedure on video is an effective way to establish a bond with audiences. Microcelebrity success is dependent on audience connection, and the surrender of privacy enables audience members to feel as though they have a personal connection with microcelebrities (Raun 2010). This authenticity through intimacy tells a very personal transgender experience to a larger audience who may be unfamiliar with medical procedures transgender people undergo in their transition.

By utilizing her perspectives and experiences as a trans woman, White establishes emotional intimacy with her audience. She rarely places herself in a vulnerable position with her audience, but she is candid in her experiences as a trans woman and how it has affected her relationships or mental health. In one of her videos, White (2020) updates her followers on her attempt to have a child with her partner using her gametes. White first announced she would stop taking hormones two years prior on YouTube and expressed her desire to have a biological child. White claims pausing her hormone intake reversed aspects of her transition; her skin and hair became oily, her hairline receded, and her body hair became thicker. Given how long she had been transitioning with hormones, doctors informed her she was sterile and could no longer produce biological children. This personal anecdote of her feelings during this experience is intimate and creates authenticity; her disappointment in knowing she cannot have children comprised of her gametes is real and the audience recognizes authenticity in this self-disclosure. In this candidness, White and Wynn contribute their experiences to public knowledge of transgender people. Advocating for medical transition and informing transgender and cisgender audiences in a vulnerable manner is not simple, and these videos are resources. Intimacy as an openly transgender individual is a political action in a world where identity is highly politicized.

\section{Conclusion}

This research examines how social media becomes a tool for digital activism and how minorities can advocate for their social identity. Microcelebrity tactics have allowed Wynn and White to attract audiences to share their ideas, encouraging further dissemination of information. This self-broadcasting holds political power in a world where transgender people's autonomy and well-being is continually threatened. Self-expression to advocate for one's identity can be a form of digital activism through audience engagement. Participatory media is a tool, and minorities who platform themselves can mobilize a listening audience to action and information sharing. White and Wynn's methods of delivering their viewpoints popularize their agendas for the transgender community and increase dialectics of transgender rights and advancement.

As the public gains more awareness and understanding of transgender individuals, more legitimate sources of information pertaining to gender identity and expression will establish and proliferate. Transgender people populating this body of knowledge out of a desire to share is social activism. While relegated to networked technologies, this does not make the documentation any less purposeful or legitimate.

Posturing as an informed or trusted figure can influence an audience to see the speaker as a prominent figure for the social movement they speak on behalf of. Future research of participatory technology as a tool for digital activism would benefit exploring other minority groups, within or outside of transgender spaces. This study does not examine the results of these efforts or provide a way to define what success looks like for a digital activist, as it would be difficult to measure and define beyond view count and following size. As more communication takes place on 
computer-mediated technologies, it must be acknowledged that these interactions do not take place within a vacuum, and effects are felt offline. We cannot measure each instance of influence watching a 40-minute video on YouTube has on the hundreds of thousands of people that watch them. Wynn and White's influences will last as long as they continue to produce content to attract the desired audience, practice microcelebrity techniques, and maintain the accessibility of their content for the public.

\section{Limitations}

Deleted tweets and videos challenged the data gathering process in this study. At one point, Blaire White wiped many of the tweets from her account and they could no longer be sourced or publicly accessible. It was too late to utilize the Internet Archive's Wayback Machine to create a saved copy of the pages for future reference, and those pages can then be removed by request, rendering them impermanent. Digital resources are only as permanent as their authors and the hosts allow. Instagram being more visual-based lent better results, so Twitter was ultimately abandoned as a reference for content analysis. Wynn also deleted several of her videos from YouTube published prior to her transition, more than one of which was referenced for this study at some point. It is not unusual for transgender individuals to resent their former manners of expression or identity, but there was still enough material from both parties to provide a cohesive qualitative analysis. It is not impossible to say the source materials for this study may not be available years down the line, but the matter of digital preservation and archiving is an entirely different matter. While Wynn (2017) archived transcripts for videos she has pulled from her YouTube, transcripts do not preserve the audio-visual medium accompanying the text.

Wynn also produces lengthier videos than White. The longest video discussed in this paper was 34 minutes in length (Wynn 2019b) and the longest one chosen for White was 23 minutes (White 2021). This is likely because Wynn's videos are scripted and have more planning involved whereas White takes a more intimate approach with her screen presence. White produces videos faster as a result, and this difference is important when considering the content of their videos and production rate.

As stated earlier in this article, the transgender experience is not uniform, and not every transgender individual agrees on solutions for the same issue. Wynn and White are adversarial on issues of contention, and even they have people who disagree with them and their ideas. The subjects of this study are two members of a larger global community; those interested in expanding upon this study would benefit from exploring transgender experiences with more diversity, such as transgender women of color, transgender men, or individuals who identify outside the strict binary of male and female.

\section{Acknowledgments}

The author thanks all faculty of The College of Saint Rose's Communications Department for fostering the development of skills and work ethic that made this paper possible. The author also expresses gratitude to peer reviewers from the International Communication Association's Annual Communications Conference in 2020 for their feedback and the opportunity to present this work to an international audience in its earlier stage. The author would also like to thank Daharsh of the Journal of Student Research for financial assistance necessary to publish this paper.

\section{References}

Cammaerts, B. (2015). Social media and activism. In R. Mansell, \& P. H. Ang (Eds.), The international encyclopedia of Digital Communication and Society. Wiley. Credo Reference: https://doi.org/10.1002/9781118767771.wbiedcs083 
Cox, C. (2021 April 8). As arkansas bans treatments for transgender youth, 15 other states consider similar bills. USA Today. https://www.usatoday.com/story/news/politics/2021/04/08/states-consider-bills-medicaltreatments-transgender-youth/7129101002/

Daskal, E. (2018). Let's be careful out there...: How digital rights advocates educate citizens in the digital age. Information, Communication \& Society, 21(2), 241-256. doi:10.1080/1369118X.2016.1271903

Deckers, E., \& Lacy, K. (2018). Branding yourself: How to use social media to invent or reinvent yourself. Pearson Education.

Diani, M. (1992), The concept of social movement. The Sociological Review, 40, 1-25. https://doi.org/10.1111/j.1467-954X.1992.tb02943.x

Duffy, B. E., \& Hund E. (2015). Having it all' on social media: Entrepreneurial femininity and self-branding among fashion bloggers. Social Media + Society. https://doi.org/10.1177/2056305115604337

Flores, A.R., Herman, J.L., Gates, G.J., \& Brown, T.N.T. (2016). How many adults identify as transgender in the united states? The Williams Institute.

Gamson, W. A., and Wolfsfeld G. (1993). Movements and Media as Interacting Systems. The Annals of the American Academy of Political and Social Science, 528, 114-125. JSTOR, www.jstor.org/stable/1047795

Grant, Jaime M., Lisa A. Mottet, Justin Tanis, Jack Harrison, Jody L. Herman, and Mara Keisling (2011). Injustice at every turn: a report of the national transgender discrimination survey. National Center for Transgender Equality and National Gay and Lesbian Task Force.

Green, E., Benner, K., \& Pear, R. (2018, October 21). 'Transgender' could be defined out of existence under trump administration. The New York Times. https://www.nytimes.com/2018/10/21/us/politics/transgender-trumpadministration-sex-definition.html

Krishnakumar, P. (2021, April 15). This record-breaking year for anti-transgender legislation would affect minors the most. CNN. https://www.cnn.com/2021/04/15/politics/anti-transgender-legislation-2021/index.html

Jerslev, A. (2016). In The Time of the Microcelebrity: Celebrification and the YouTuber Zoella. International Journal of Communication, 10 (19) https://ijoc.org/index.php/ijoc/article/view/5078/1822

Matich, M., Rachel A, and Parson, E. (2019). “\#freethenipple - Digital activism and embodiment in the contemporary feminist movement" Consumption Markets \& Culture, 10 pp. 337-362. https://doi.org/10.1080/10253866.2018.1512240

Raun, T. (2018). Capitalizing intimacy: New subcultural forms of micro-celebrity strategies and affective labour on youtube." Convergence, 24(1) 99-113 https://doi.org/10.1177/1354856517736983

Raun, T. (2010). Screen-birth: Exploring the transformative potential in trans video blogs on youtube. Graduate Journal of Social Science, 7(2) 113-130 http://gjss.org/issues/07/02

Stryker, S. (2017). Transgender History: The Roots of Today's Revolution (2nd Ed.). Seal Press.

Tavernise, S. (2017, November 23). Ben shapiro, a provocative 'gladiator,' battles to win young conservatives." The New York Times. https://www.nytimes.com/2017/11/23/us/ben-shapiro-conservative.html

Urquhart, E. (2021, February 1). An "ex-detransitioner" disavows the anti-trans movement she helped spark. Slate. https://slate.com/human-interest/2021/02/detransition-movement-star-ex-gay-explained.html

Van Laer, J., \&Van Aelst, P. (2010). Internet and social movement action repertoires.” Information, Communication \& Society, 13(8) 1146-1171. https://doi.org/10.1080/13691181003628307

White, B. (2015, November 27). "Blaire white" YouTube. https://www.youtube.com/c/BlaireWhiteX/

White,B. (2016, December 31). "Blaire black" YouTube. https://www.youtube.com/c/BlaireJoey

White, B. (2021, March 9). let me tell you how insane eating disorders are- $i$ took these pics a couple months ago on vacation and [Photos]. Instagram. https://www.instagram.com/p/CMNQ7QXJzrm/

White, B. (2021, May 26). "My life felt ruined" - talk w/ detransitioned woman [Video]. YouTube. https://www.youtube.com/watch?v=xJNAD6dJanA

White, B. (2020, November 10). The truth about why i'm still not a parent [Video]. YouTube 
White, B. (2020, July 1). Trying to enjoy the summer from hell where everything online + real life feels so dark and scary $\bullet$ [Photo]. Instagram. https://www.instagram.com/p/CCG2iH9Jtv7/

White, B. (2021, May 14). Responding to "blaire white hates non-binary people" [Video]. YouTube. https://www.youtube.com/watch?v= CUf2vIz2Y4

White, B. (2021, February 7). This is why the trans community isn't respected (rant) [Video]. YouTube. https://www.youtube.com/watch?v=6lhcud6nccE

White, B. (2018, November 3). Trump removing trans rights?? (the truth) [Video]. YouTube. https://www.youtube.com/watch?v=IXRRIG8o3wg

White, B. [@msblairewhite]. (n.d.) Instagram. https://www.instagram.com/msblairewhite/

Wynn, N. [@contrapoints]. (2020, March 11). An unused frame from “opulence.” this was the video where $i$ put the most effort into pure visual spectacle. it [Photo]. Instagram. https://www.instagram.com/p/B9mrkuWgSgp/

Wynn, N. (2017, December 31). Archived Transcripts - Contrapoints. Contrapoints. https://www.contrapoints.com/transcripts/archives

Wynn, N. (2011 February 3). “ContraPoints.” YouTube. https://www.youtube.com/user/ContraPoints

Wynn, N. (2019, May 22). Beauty [Video]. YouTube. https://www.youtube.com/watch?v=n9mspMJTNEY

Wynn, N. [@contrapoints] (2020, April 24). Finishing up work on a set! i can't promise a release date yet but $i$ can promise a big show [Photo]. Instagram. https://www.instagram.com/p/B_WfZQkl1nf/

Wynn, N. (2020, August 3). It's my three year tranniversary. the third year was the hardest. hoping to get it together in the fourth [Photo]. Instagram. https://www.instagram.com/p/CDagp3vAxYv/

Wynn, N. (2018, November 2). Pronouns [Video]. YouTube. https://www.youtube.com/watch?v=9bbINLWtMKI

Wynn, N [@contrapoints] (2020 January 25). \#WeAreHere the trump administration wants to make it legal to fire workers just because they are lgbtq +. as you read [Video]. Instagram.

https://www.instagram.com/p/B7wpkEFg5vt/

Wynn, N. (2018, June 2). Tiffany tumbles [Video]. YouTube. https:/www.youtube.com/watch?v=j1dJ8whOM8E

Wynn, N. (2019, July 1). Transtrenders [Video]. YouTube. https://www.youtube.com/watch?v=EdvM pRfuFM

Wynn, N. [@contrapoints] (n.d.). Instagram. https://www.instagram.com/contrapoints/

Unisex / Men's T-Shirts | Blaire White (n.d.) Spring. https://blaire-white.creator-spring.com/

T-shirts by Contrapoints - TeePublic Store | TeePublic (n.d.). TeePublic.

https://www.teepublic.com/stores/contrapoints 